\title{
Erratum zu: Best, Heinrich/Higley, John (Hrsg.): The Palgrave Handbook of Political Elites, 698 S., Palgrave Macmillan, London 2018.
}

\author{
Sylvia Veit
}

Online publiziert: 14 . Oktober 2021

(C) Der/die Autor(en) 2021

\section{Erratum zu:}

Neue Polit. Lit. 2020

https://doi.org/10.1007/s42520-020-00209-2

Der Artikel „Best, Heinrich/Higley, John (Hrsg.): The Palgrave Handbook of Political Elites, 698 S., Palgrave Macmillan, London 2018.“ von Sylvia Veit wurde ursprünglich ohne „Open Access“ auf der Internetplattform des Verlags publiziert. Nach der Veröffentlichung in Band 65 Heft 1 pp. 193-196 hat sich die Autorin für eine „Open Access“-Veröffentlichung entschieden. Das Urheberrecht des Artikels wurde deshalb am 17. September 2021 in (C) Der/die Autor(en) 2020 geändert. Der Artikel wird nun unter der Creative Commons Namensnennung 4.0 International Lizenz veröffentlicht, welche die Nutzung, Vervielfältigung, Bearbeitung, Verbreitung und Wiedergabe in jeglichem Medium und Format erlaubt, sofern Sie den/die ursprünglichen Autor(en) und die Quelle ordnungsgemäß nennen, einen Link zur Creative Commons Lizenz beifügen und angeben, ob Änderungen vorgenommen wurden. Die in diesem Artikel enthaltenen Bilder und sonstiges Drittmaterial unterliegen ebenfalls der genannten Creative Commons Lizenz, sofern sich aus der Abbildungslegende nichts anderes ergibt. Sofern das betreffende Material nicht unter der genannten Creative Commons Lizenz steht und die betreffende Handlung nicht nach gesetzlichen Vorschriften erlaubt ist, ist für die oben aufgeführten Weiterverwendungen des Materials die Einwilligung des jeweiligen Rechteinhabers ein-

Die Online-Version des Originalartikels ist unter https://doi.org/10.1007/s42520-020-00209-2 zu finden.

Sylvia Veit $(\square)$

Kassel, Deutschland

E-Mail: sveit@uni-kassel.de 
zuholen. Weitere Details zur Lizenz entnehmen Sie bitte der Lizenzinformation auf http://creativecommons.org/licenses/by/4.0/deed.de.

Funding Open Access funding enabled and organized by Projekt DEAL.

Open Access Dieser Artikel wird unter der Creative Commons Namensnennung 4.0 International Lizenz veröffentlicht, welche die Nutzung, Vervielfältigung, Bearbeitung, Verbreitung und Wiedergabe in jeglichem Medium und Format erlaubt, sofern Sie den/die ursprünglichen Autor(en) und die Quelle ordnungsgemäß nennen, einen Link zur Creative Commons Lizenz beifügen und angeben, ob Änderungen vorgenommen wurden.

Die in diesem Artikel enthaltenen Bilder und sonstiges Drittmaterial unterliegen ebenfalls der genannten Creative Commons Lizenz, sofern sich aus der Abbildungslegende nichts anderes ergibt. Sofern das betreffende Material nicht unter der genannten Creative Commons Lizenz steht und die betreffende Handlung nicht nach gesetzlichen Vorschriften erlaubt ist, ist für die oben aufgeführten Weiterverwendungen des Materials die Einwilligung des jeweiligen Rechteinhabers einzuholen.

Weitere Details zur Lizenz entnehmen Sie bitte der Lizenzinformation auf http://creativecommons.org/ licenses/by/4.0/deed.de. 